\title{
La especialización de la producción agrícola en Sinaloa y los grupos de presión
}

DOI: 10.32870/mycp.v6i18.641

Joaquín G. Morales Valderrama*

\section{I}

\section{ntroducción}

Sinaloa es un estado de México con eminente vocación agropecuaria. En 1998 aportó 7.7 por ciento del Valor Agregado Bruto Total agropecuario (VABT) del país, lo que le significó 22 por ciento del VABT de la economía estatal.

Le debe su vocación agrícola a las importantes obras hidráulicas (presas, canales) creadas a partir de la consolidación del gobierno, surgido de la revolución mexicana (1920). Situada en la costa norte occidental del país, Sinaloa tiene ante sí la cuenca del pacífico y, con ello, abiertas las posibilidades de comercio en el nuevo milenio. Culiacán, su capital, tiene nexos carreteros (a $720 \mathrm{~km}$ de distancia) con Guadalajara, la segunda ciudad más importante de México y, hacia el norte, con la frontera sur de Estados Unidos, a 974 $\mathrm{km}$. Hasta ahora, su comercio agropecuario (cereales y carnes de ave, puerco, bovino) se ha dirigido a surtir el mercado interno del país, como Guadalajara y la ciudad de México, y al mercado externo, jitomate a los EU, y garbanzo a la comunidad europea. Su infraestructura portuaria también le ha permitido hacer exportaciones iniciales de trigo y maíz blanco a Centroamérica.

Este artículo presenta la estructura de cultivos de la entidad y realiza una revisión histórica para encontrar las razones que expliquen por qué los agricultores de Sinaloa se han especializado en ciertos productos: ¿razones de mercado? ¿Políticas de fomento desarrollados por el gobierno estatal o federal?

* Profesor investigador del Centro Regional Universitario de Occidente, de la Universidad Autónoma Chapingo.
También discute la polémica teórica que enfrenta el fomento de los cultivos de exportación contra los cultivos de consumo interno.

Los resultados indican que la actual composición de los productos que se siembran en Sinaloa, se debe a la presencia de por lo menos tres factores que han condicionado la decisión de los agricultores: a) una sociedad productiva organizada, con posibilidades de negociar sus proyectos productivos con el gobierno y con mercados nacionales e internacionales; b) incentivos de mercado y de innovación tecnológica específica en ciertos cultivos, y c) acción del gobierno, con fuertes apoyos económicos al mercado, que favorece el desarrollo para unos cultivos y no de otros. Es decir, los resultados muestran que son insuficientes las razones con base en la rentabilidad diferenciada de productos como razón única de la toma de decisiones de los productores (un libre mercado actuante); la institucionalidad (reglas de juego) en Sinaloa implica una sociedad agropecuaria compleja que vincula mercado con actores sociales. El artículo cubre el período de 1984 a 1999, el cual analiza la rentabilidad diferencial entre los principales cultivos para tratar de explicar la razón que movió al productor a sembrar determinados productos. También investiga las políticas de gobierno que influyeron en su desarrollo, como dotar de un mayor presupuesto para la compra de maíz y su comercialización. Y, finalmente, analiza la estructura organizativa de los productores de la entidad.

\section{El patrón de cultivos de Sinaloa}

Al observar los datos de uso de la superficie agrícola de Sinaloa y su producción, podemos 
considerar como inexacta la afirmación de que en esa zona está presente un "modelo agroexportador instituido en Sinaloa". ${ }^{1}$ Los datos de la entidad más bien reflejan la existencia un modelo bimodal de agricultura, en la cual la exportación convive con productos dirigidos a un fuerte mercado interno.

En términos generales, los datos sobre el patrón de cultivos indican que Sinaloa es una de las entidades más productivas del país, especializándose tanto en la producción de cultivos de exportación (jitomate, garbanzo), como en cultivos básicos (maíz, frijol, trigo). Al considerar diversos grupos de alimentos, los granos ocupan la mayor parte de la superficie cosechada con 66 por ciento (760 mil hectáreas); el bajo valor de estos productos por unidad de producción (tonelada), se evidencian al aportar sólo el 37 por ciento del valor de la producción total agrícola anual (año agrícola 2000).

El segundo grupo en importancia son las hortalizas, que aunque sólo ocupan ocho por ciento de la superficie cosechada, lo que implica alrededor de 95 mil hectáreas, contribuye con 47 por ciento de la producción (valor) estatal.

Resalta el grupo del forraje, sobre todo por usar el 12 por ciento de la superficie cosechada (140 mil hectáreas), aunque su valor de producción es muy bajo: dos por ciento estatal.
Es interesante observar la importancia de cultivos específicos, en el 2000, al considerar el valor de la producción: el maíz aportó 3.5 millones de pesos; jitomate, 3.3; papa, 1.3; chile, 1.0; garbanzo, 0.84; trigo, 0.57; caña de azúcar, 0.53; calabaza, 0.48; frijol, 0.44; $\mathrm{y}$, en décimo lugar, el sorgo que aportó 0.37 millones de pesos. Los cultivos dirigidos al mercado interno se mezclan con los cultivos de exportación ${ }^{2}$ en cuanto a la importancia económica.

Estos mismos datos, vistos mediante la importancia que asumen los productos en el contexto nacional, nos indican que Sinaloa ocupa el segundo lugar en la producción de maíz, ${ }^{3}$ primero en jitomate y papa, segundo en chile verde, cuarto en trigo, séptimo en caña de azúcar y segundo en frijol. Otros cultivos que no tienen peso en el patrón de cultivos interno (ocupación de superficie y producción comparativa), pero que destacan en el contexto nacional son: el ajonjolí, primer lugar; soja, segundo, y arroz y cártamo, que ocupan el tercer puesto en la producción nacional.

\section{Las transformaciones del patrón de cultivos}

Para observar el cambio en el patrón de cultivos compararemos dos momentos: los inicios de los ochenta, con el dato del promedio trianual $1983 / 1985$, y finales de los noventa, con el promedio trianual $1997 / 1999 .{ }^{4}$

\section{Cuadro 1}

Sinaloa: principales grupos de cultivos (2000)

\begin{tabular}{lrrrr}
\hline & $\begin{array}{l}\text { Superficie } \\
\text { cosechada } \\
\text { (hectáreas) }\end{array}$ & $\begin{array}{l}\text { Valor de la } \\
\text { producción } \\
\text { (miles de pesos) }\end{array}$ & $\begin{array}{l}\text { Superficie } \\
\text { cosechada } \\
\%\end{array}$ & $\begin{array}{l}\text { Valor de la } \\
\text { producción } \\
\%\end{array}$ \\
\hline Granos & 756,011 & $5,747,247$ & 67.4 & 37.1 \\
Oleaginosas & 54,268 & $1,886,663$ & 4.8 & 1.2 \\
Hortalizas & 94,655 & $7,313,388$ & 8.4 & 47.2 \\
Fibras indust. & 32,306 & 557,166 & 2.9 & 3.6 \\
Forrajes & 138,691 & 241,976 & 12.4 & 1.6 \\
Varios & 45,659 & $1,323,416$ & 4.1 & 8.5 \\
Total Sinaloa & $1,121,589$ & $15,480,856$ & 100.0 & 100.0 \\
\hline
\end{tabular}

Fuente: anexo estadístico del Tercer Informe de Gobierno, C. Juan S.

Millán, 2001, p. 120. 
Cuadro 2

Sinaloa: superficie cosechada de los cultivos desplazados

hectáreas

\begin{tabular}{lrrrr}
\hline & Superficie 1984 & Superficie 1998 & Dif. 1998-1984 & $\% 1998 / 1984$ \\
\hline Trigo & 187,808 & 48,390 & 139,417 & 26.0 \\
Soja & 195,033 & 23,243 & 171,789 & 12.0. \\
Cártamo & 127,265 & 23,670 & 103,596 & 19.0 \\
Arroz & 63,056 & 8,039 & 55,018 & 13.0 \\
& & & & \\
Grupo & 573,163 & 103,342 & 469,821 & 18.0 \\
\hline
\end{tabular}

Fuente: Elaboración a partir de datos de Aguilar 1999, "Diecisiete años de producción maicera en Sinaloa, 1980-1997", Ciencia y Universidad, núm. 12 (tercera época), IIES Universidad Autónoma de Sinaloa, junio, 1999 Sinaloa, México, p. 109.

El dato de inicios de los ochenta reflejará el patrón de cultivos de Sinaloa, soportado en la proliferación de oleaginosas y cultivos, cuyos productos y subproductos eran destinados a la industria de alimentos balanceados. En ese entonces, el trigo todavía preservaba parte de su época de gloria (la revolución verde), así como las hortalizas (sobresale el jitomate) que ya tenían una fuerte presencia.

En los ochenta, con la entrada al Acuerdo General de Aranceles y Comercio (GATT, por sus siglas en inglés), México inició una serie de cambios en los aranceles de importación, que primero afectaron a las oleaginosas y, en 1990, cuando sólo fue preservado el precio de garantía del maíz y frijol, también afligió la producción de sorgo y trigo.

El trienio de 1997-1999 ya refleja parte de los cambios de la política de liberación económica, así como los efectos de la agudización de un patrón de desarrollo (que no inicia con el neoliberalismo) que induce a una mayor diferenciación social y a la especialización de zonas agrícolas en busca de una mayor rentabilidad (independientemente de cualquier cultivo).

El análisis de 14 años, con datos del patrón de cultivos sinaloense, arroja un comportamiento diferenciado de tres grupos de productos: los que fueron desplazados y cuyo auge correspondió al de la revolución verde en ese estado (trigo, soja, cártamo); otro grupo que se sostiene e incrementa su importancia (como el jitomate), y el último grupo cuyos cultivos se expanden de forma inusitada y que desplazan y cambian el perfil productivo de la región (maíz, frijol y sorgo).

\section{Los cultivos desplazados 5}

En 1984 (en referencia al promedio trianual) el trigo, la soja, el cártamo y el arroz ocupaban 573 mil hectáreas ${ }^{6}$ en Sinaloa, que generaban 1.6 millones de toneladas. Catorce años después (1998) sólo ocupaban 103 mil hectáreas, con una producción de $347 \mathrm{mil}$ toneladas. Es decir, la superficie se redujo al 18 por ciento y la producción se contrajo al 22 por ciento, respecto a 1982 .

Por cultivos puede apreciarse más estas bajas:

La caída de la superficie es similar en todo el grupo analizado (menor en trigo) en proporción a la superficie que se cosechaba en 1982 , ya que para 1998 ésta se había reducido en un 82 por ciento.

El análisis del comportamiento de la producción muestra también una tendencia decreciente. La reducción en la producción, de menos 78 por ciento, fue un poco menos acentuada, sobre todo porque se logró mejorar el rendimiento en los cultivos. Es interesante observar que pese a la marcada caída del cártamo y arroz, reducidos a 33 y 26 por ciento, respectivamente, Sinaloa todavía ocupa el tercer lugar en la producción nacional. Similar 
Cuadro 3

Sinaloa: producción desplazada por tipo de cultivo (toneladas)

Fuente: Elaboración a partir de datos de Aguilar op. cit.

\begin{tabular}{|c|c|c|c|c|}
\hline & 1984 & 1998 & dif.1998-1984 & \% 1998/1984 \\
\hline Trigo & 838,818 & 233,498 & 605,321 & 28.0 \\
\hline Soja & 375,004 & 45,337 & 329,667 & 12.0 \\
\hline Cártamo & 81,118 & 26,626 & 54,482 & 33.0 \\
\hline Arroz & 268,585 & 41,961 & 226,624 & 26.0 \\
\hline Grupo & $1,563,525$ & 347,432 & $1,216,093$ & 22.0 \\
\hline
\end{tabular}

que este aumento en la producción corresponde a la superficie incrementada (crecimiento extensivo), mas que al aumento de los rendimientos por unidad de superficie. Los rendimientos en 1983 eran de 35.1 toneladas por hectárea, mientras que en 1999 fueron de 28.4 toneladas. Maticemos los resultados anteriores (datos puntuales anuales) al observar la serie histórica y con medias bianuales:

Como puede observarse en el cuadro 4, la superficie en las dos décadas bajo estudio ha variado, de 20 mil hasta 30 mil hectáreas, con una fluctuación cercana a las $27 \mathrm{mil}$ hectáreas. La producción tiene su punto más bajo con 700 mil toneladas, a principios de los ochenta, y su punto más alto a principios de los noventa, con 940 mil toneladas.

Los rendimientos, salvo el pico de 35 toneladas de $81 / 83$ y la baja de 31 toneladas de $92 / 95$, han fluctuado alrededor de las 32 toneladas por hectárea. Esto representa un estancamiento en dos décadas, de los rendimientos del jitomate. Al analizar los datos aportados, puede afirmarse que el jitomate es un cultivo que no aparece con la política neoliberal y, en el contexto de dos décadas de apertura comercial, este producto ya había sido desarrollado a principios de los

\section{Cuadro 4} continúa en términos relativos, aunque se observa un desarrollo paulatino de la superficie cosechada de jitomate y, por ende, de su producción. En 1999 fueron cultivadas 31.4 mil hectáreas, 10 mil más que 1983. Es decir, la superficie cultivada creció 32 por ciento. La producción aumentó de 756 mil toneladas, en 1983, a 892 mil en 1999, 136 mil toneladas adicionales, lo que representa un 18 por ciento de incremento con respecto al año base. Hay que destacar
Sinaloa: comportamiento del jitomate

\begin{tabular}{llll}
\multicolumn{5}{c}{ Sinaloa: comportamiento del jitomate } \\
\hline $\begin{array}{l}\text { Promedios } \\
\text { bianuales }\end{array}$ & $\begin{array}{l}\text { Superficie } \\
\text { cosechada } \\
\text { hectáreas }\end{array}$ & Producción & Rendimiento \\
& $19,899.50$ & $703,127.50$ & 35.3 \\
\hline $81 / 83$ & $28,566.50$ & $901,593.50$ & 31.9 \\
$85 / 86$ & $28,770.50$ & $936,840.00$ & 32.6 \\
$88 / 89$ & $29,411.50$ & $939,304.50$ & 32.3 \\
$90 / 91$ & $27,608.00$ & $853,708.50$ & 30.9 \\
$93 / 95$ & $25,051.50$ & $843,991.00$ & 34.0 \\
$96 / 97$ & $28,364.00$ & $893,731.50$ & 31.9 \\
\hline $98 / 99$ &
\end{tabular}

Fuente: Elaboración a partir de datos de Aguilar 1999, op. cit., pp. 159 y 160. 
Cuadro 5

Sinaloa: superficie de los cultivos en expansión

(hectáreas)

\begin{tabular}{lrrrr}
\hline & 1984 & \multicolumn{2}{c}{1998} & dif. $1998-1984 \% 1998 / 1984$ \\
\hline Maíz & 86,209 & 367,449 & 281,240 & 326 \\
Frijol & 75,249 & 168,349 & 93,100 & 124 \\
Sorgo & 128,440 & 215,540 & 87,100 & 68 \\
& & & & \\
Grupo & 289,898 & 751,338 & 461,440 & 159 \\
\hline
\end{tabular}

Fuente: Elaboración propia con datos de Aguilar 1999.

ochenta; a lo largo de esa década no presenta un extraordinario impulso a su producción de 27 por ciento o rendimiento menos 10 por ciento El jitomate se afianza en estas dos décadas, con base en la expansión de la superficie (42 por ciento adicional), dirigiéndose sobre todo a competir con la producción de Florida, en Estados Unidos, cuya principal carta de presentación no es la productividad, sino la calidad. Los estudios de Trujillo ${ }^{7}$ señalan que su calidad es la que mantiene al jitomate de Sinaloa en la unión americana.

\section{Los cultivos que se} desarrollan

El maíz es, sin duda, el fenómeno del segundo lustro de los ochenta y durante los noventa en Sinaloa. Como lo afirma Aguilar ${ }^{8}$ en su puntual trabajo, el maíz dejó de estar asociado a la agricultura de temporal y a productores de bajos recursos. El maíz se convirtió en un fenómeno empresarial que ocupa el 40 por ciento $^{9}$ de las mejores tierras (de riego) en Sinaloa.

Como indican las cifras del cuadro 5, en 1984 se partía de una superficie de 86 mil hectáreas, para llegar a 367 mil en 1998, multiplicándose por cuatro su extensión. La expansión de tierra estuvo acompañada de un mejor manejo técnico, de modo que los rendimientos también se multiplicaron de forma espectacular: de 1.64 toneladas por hectárea, en 1984, a 6.1 toneladas en 1998. El resultado de ambos elementos, superficie y manejo técnico, provocó un aumento de la producción que se multiplicó 17 veces, de 128 mil toneladas a 2 257 mil toneladas.

La nueva presencia del maíz sinaloense afectó el mercado de la mayor parte del país. Sinaloa pasó a producir 14 por ciento de la producción nacional, ${ }^{10}$ además entró al mercado con tres ventajas: a) es el único que comercializa más de 90 por ciento de su cosecha; b) su producción ingresa al mercado a mediados del año, cuando apenas está sembrándose el principal volumen de maíz nacional, el de temporal, que también representa para la industria la posibilidad de ahorrarse el almacenaje, y c) su grano es de una calidad homogénea por provenir de semillas híbridas y cosecharse mediante trilladoras mecánicas.

En el período analizado, el frijol es el segundo cultivo que se expande en Sinaloa, acentuándose a partir de 1994, al mantener una 
superficie cultivada superior a las cien mil hectáreas. En este caso los rendimientos no varían notablemente, ya que pasan de 1.15 toneladas a 1.28 toneladas por hectárea. La producción se incrementa al multiplicarse por 2.5 veces, al pasar de 87 mil toneladas a 216 mil toneladas.

El sorgo es el último cultivo en expansión. Su crecimiento es más moderado con respecto a los dos anteriores, ya que sólo se ha incrementado en 68 por ciento en cuanto a superficie, y a 61 por ciento en producción.

\section{La sustitución intercultivos}

Si se observan los números globales, el grupo de los productos desplazados (trigo, soja, cártamo, arroz) descendió su superficie en 470 mil hectáreas, mientras que el grupo en expansión (maíz, frijol, sorgo) aumentó la superficie en 461 mil hectáreas, la diferencia es de apenas 9 mil hectáreas. Puede afirmarse que la sustitución principal de cultivos ha sido entre estos grupos. Es decir, se ha dado un cambio de granos destinados a la alimentación humana y a la producción de aceites, por granos destinados a alimentación humana y a la industria de balanceados.

Este patrón de especialización corresponde a la presencia de nuevos ${ }^{11}$ arreglos institucionales (reglas del juego), que ofrecen un nuevo conjunto de opciones a los agentes productivos.

Tales arreglos pueden agruparse en:

a) Opciones de mercado y nueva rentabilidad. b) El Estado muestra nuevas señales: reorienta los subsidios y los organismos para que apoyen a uno $u$ otro producto y región.

c) Las relaciones sociales entre productores, comercializadores industriales y consumidores, que se agrupan en redes de poder (comercial, político, productivo), han influido en el mercado para que ciertos productos sean más viables que otros. Retomaremos este tema más adelante.

Los desplazamientos de granos por granos, ya sean oleaginosas, básicos o forrajeros, no es un fenómeno nuevo en México ni en Sinaloa. En los setenta, y hasta mediados de los ochenta, pudo presenciarse el desplazamiento del maíz, algodón, ajonjolí y frijol, por el de sorgo, soja, cártamo y, en menor medida, trigo; cultivos "nuevos" asociados a los sistemas agroindustriales, productores de proteína animal (aves, puercos, bovinos). En ese entonces, como ahora, fueron señaladas las "ventajas comparativas" como la política que originaba la crisis campesina de ese momento. Se denunció que privilegiaban cultivos de exportación contra la producción de básicos (Montañés, Montes de Oca, Cassio, Warman). Estudios específicos demostraron que estaba deslocalizado el problema. Los movimientos entre cultivos se debieron a una búsqueda de rentabilidad (Rodríguez Gijena ${ }^{12}$ ) dándose estos desplazamientos entre granos, oleaginosas y fibras (algodón). El caso de Sinaloa en la actualidad de nuevo nos muestra un desplazamiento intergranos que implica alrededor de 500 mil hectáreas.

Algunas razones que explican tales desplazamientos son: a) una rentabilidad

Cuadro 6

Sinaloa: producción de los cultivos en expansión (toneladas)

\begin{tabular}{|c|c|c|c|c|}
\hline & 1984 & 1998 & 1998-1984 & \% 1998/1984 \\
\hline Maíz & 141,084 & $2,256,548$ & $2,115,464$ & 1,499 \\
\hline Frijol & 86,709 & 215,651 & 128,942 & 149 \\
\hline Sorgo & 377,769 & 608,924 & 231,155 & 61 \\
\hline Grupo & 605,562 & $3,081,123$ & $2,475,561$ & 409 \\
\hline
\end{tabular}




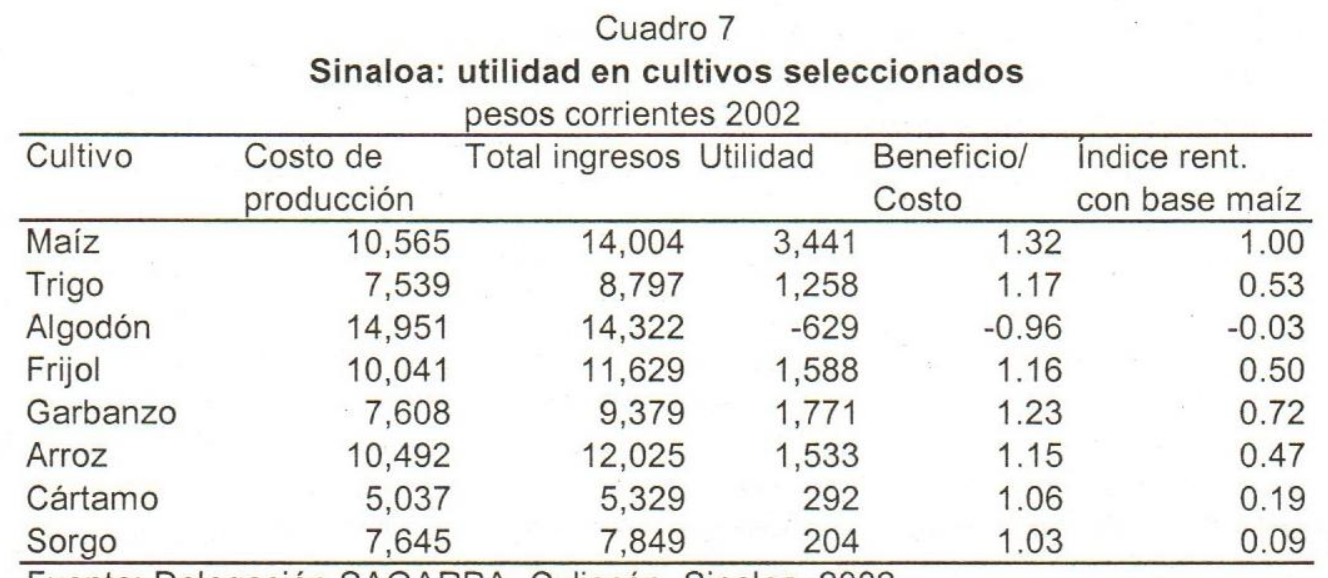

Fuente: Delegación SAGARPA, Culiacán, Sinaloa, 2002.

diferencial; b) el soporte de un precio de referencia y luego de indiferencia por parte del gobierno, durante los noventa, para el maíz y frijol; c) la compra de cultivos específicos por el gobierno durante toda la década de los noventa, que garantizó un mercado selectivo; d) las movilizaciones y creación del comité de compra, entre productores y de éstos con las autoridades, y e) la presión de industriales para tener acceso a la materia prima subsidiada.

a) Rentabilidad. Los estudios de rentabilidad todavía son inexactos, pues suponen que un agricultor es externo al proceso agrícola e ingresa para pagar todas las labores e insumos que implica el cultivo, pero esto no es así. Tampoco consideran que los costos de producción varían según el estrato de productor y si posee maquinaria propia o no. A continuación se expone un extracto de un estudio realizado por la SAGAR, en Sinaloa, para 2002, en el que pueden observarse los diferenciales de rentabilidad por tipo de cultivo.

La rentabilidad del maíz es la más alta de todos los cultivos considerados, ya que por cada peso invertido se obtiene su reposición más 32 centavos. El cultivo menos rentable, según este ejercicio, es el del sorgo que obtiene 3 centavos adicionales a la reposición de la inversión. El algodón tiene una rentabilidad negativa, ya que se pierde el cuatro por ciento de su inversión.
Si partimos de un índice construido a partir de la utilidad del maíz (ver última columna), en la cual su utilidad de 1.32 la igualamos a uno, y así mismo referimos las demás utilidades al índice propuesto, encontramos que ningún cultivo supera la rentabilidad de este grano. El garbanzo es el más cercano con un índice .75 , le sigue el frijol con un índice .50. La rentabilidad comparativa al maíz muestra los tres cultivos en expansión en el período referido. Bajo este índice también se observa una razón para el abandono del cártamo (índice .2) y algodón (índice negativo .03). En el caso del trigo, arroz y el sorgo, los datos no confirman alguna tendencia, ya que son contradictorios a la dinámica que han seguido esos cultivos.

b) El apoyo del Estado durante los noventa. Dos elementos son característicos del libre mercado y del riesgo que implica un negocio: 1) la probable variación de los precios y, con ello, 2) la mayor o menor posibilidad de encontrar compradores. Ambos factores no afectaron al maíz y frijol, pero sí a los demás productos.

Mantener el precio de garantía del frijol y maíz, a inicios de los noventa, fue el primer paso que dio el gobierno para apoyar estos cultivos. Después, los precios de garantía evolucionaron a precios de referencia, también anunciados por el gobierno, antes de iniciarse las siembras (o durante su transcurso) para culminar como precios de indiferencia (creados 


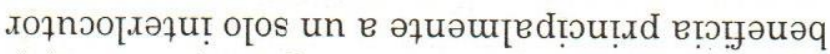
$\Lambda$ (eо[euts) uọ,

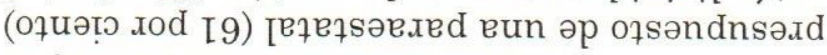

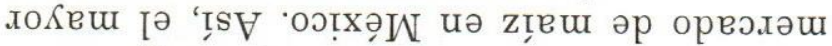

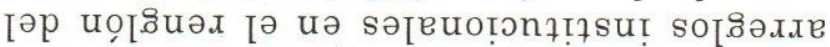

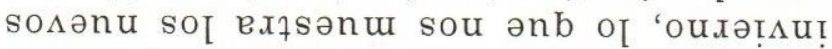

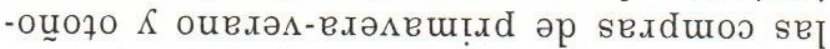

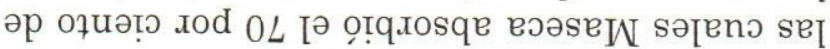

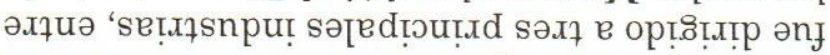

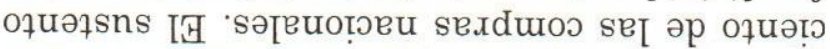

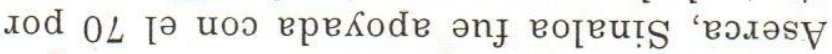

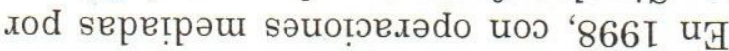

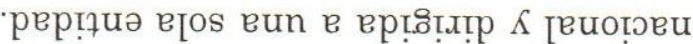

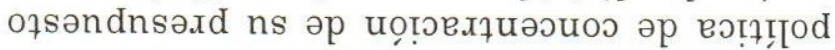
eusțu eI әиәтุuвu '(вәләs

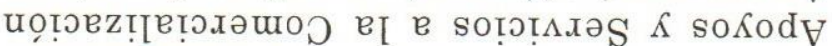

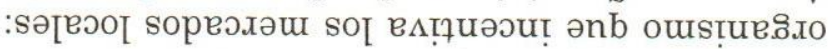

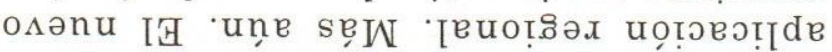

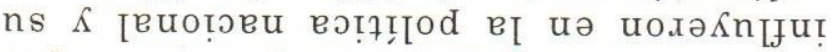

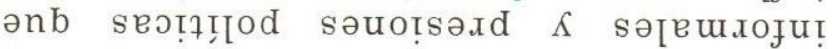

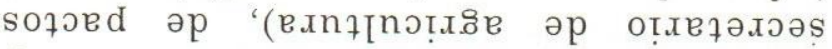

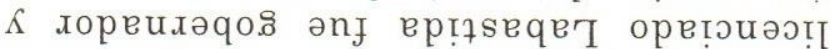

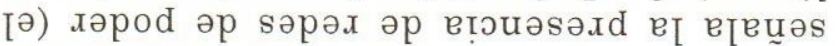

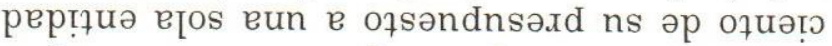

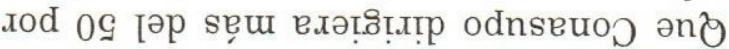

:sәрертұuә

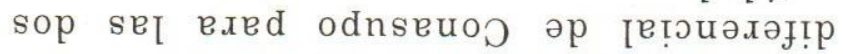

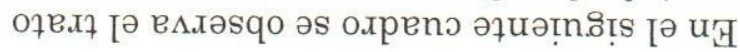

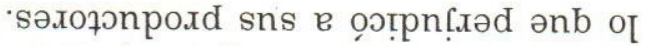

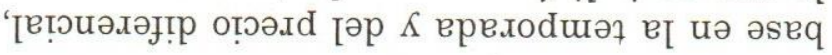

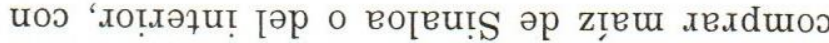

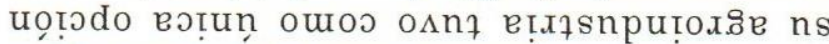

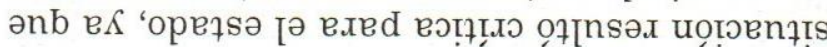

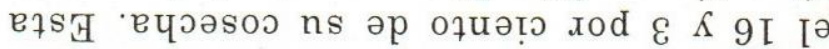

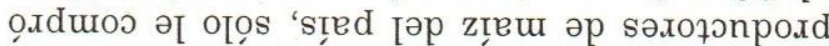
sə[edțuutxd sol əp oun 'oosțep e 'soũe

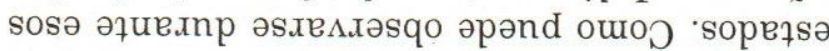

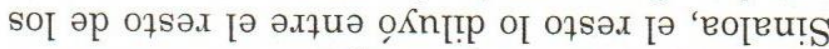

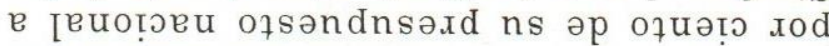

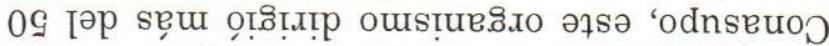

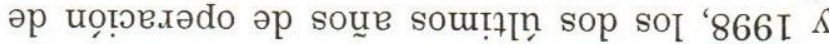

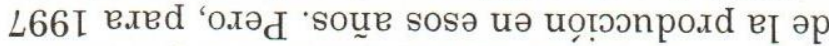

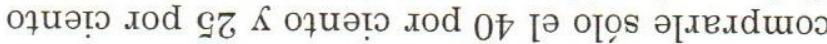

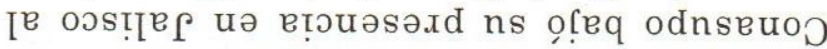
rpe[əuo7 xod sosad 0૬E I e 099 әр zteu

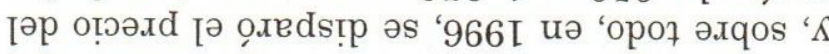

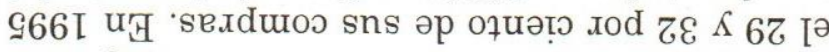

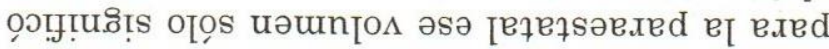
әnbune 'odnseuo xod epexduo әnf (оұนәฺ๊

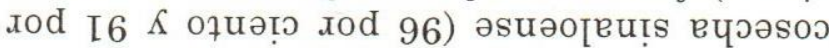

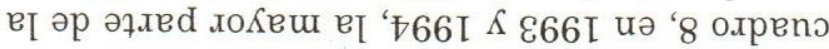

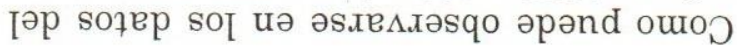

'sțed [әр sоләэтеu

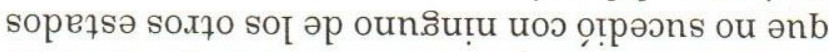

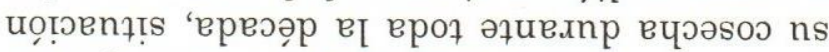

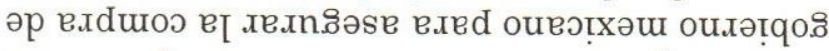

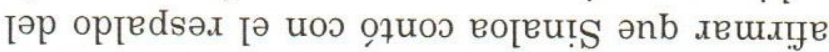

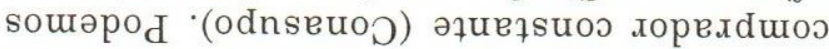

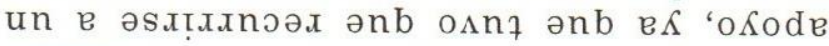

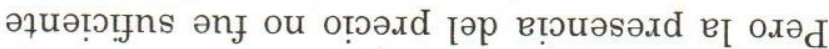

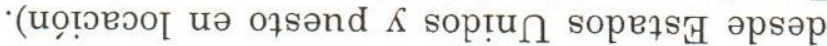

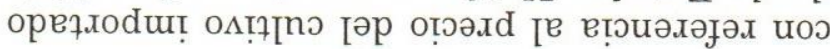

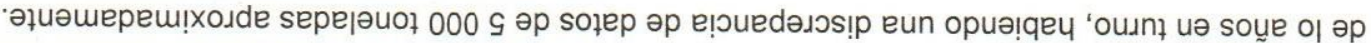

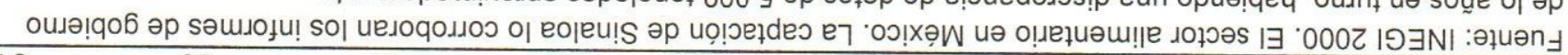

\begin{tabular}{|c|c|c|c|c|c|c|}
\hline$\downarrow G$ & OS & $\angle Z$ & $\varepsilon 乙$ & 乙E & 62 & 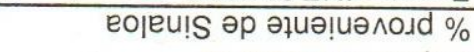 \\
\hline レ৪でャ৪レ'て & 9เナ'Z9פ'E & 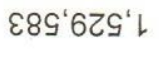 & $60 S^{\prime} E L \varsigma^{\prime} \varepsilon$ & เ96'เE6'L & †Lサ‘Sレレ'8 & ןeuo!̣eu uọıełdeว \\
\hline St & $\angle 9$ & ५乙 & $0 t$ & 16 & 96 & 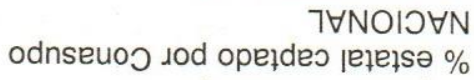 \\
\hline 00006டレ & 000‘008' L & $000^{\prime} 0 Z \triangleright$ & $000^{\prime} 0 Z 8$ & 000'0Z9'乙 & 000‘0†ย'乙 & odnseuos uọ̣ełdeo \\
\hline 000`0Z9‘乙 & $000^{\prime} 00 L^{\prime} 乙$ & $000^{\prime} 00 L^{\prime} L$ & 000`0ع0‘乙 & $000 ` 09 L^{\prime} 乙$ & $000^{\prime} 0 S t^{\prime} Z$ & uọ!osnpodd \\
\hline$\varepsilon$ & 9l & 9 & $\angle Z$ & $9 t$ & St & 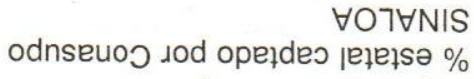 \\
\hline $000 ` 08$ & $000^{\prime} 0 \varepsilon \varepsilon$ & 000‘OSL & $000 \div 019$ & $000 ` 086$ & 000‘080‘ L & odnseuoj uọ!oełdej \\
\hline 000‘08L'乙 & 000‘0<0‘乙 & 000'0عE'乙 & 000`0ع乙`乙 & 000`0عL'乙 & 000'08ع'乙 & uọ!oonposd \\
\hline 2866l & $\angle 66 \mathrm{l}$ & 9661 & & & & OOSI $\forall$ R \\
\hline & & & $966 \mathrm{~L}$ & $\frac{\text { t66l }}{\text { epe(әиов) }}$ & $\varepsilon 66 \mathrm{~L}$ & \\
\hline
\end{tabular}

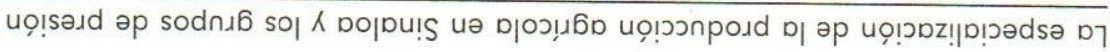


Cuadro 9

ASERCA: programas de apoyo a la comercialización de maíz blanco 1998

\begin{tabular}{|c|c|c|c|c|c|c|}
\hline Programa & $\begin{array}{l}\text { Meta } \\
\text { Captación } \\
\text { Programada } \\
\end{array}$ & $\begin{array}{l}\text { Condiciones } \\
\text { del programa }\end{array}$ & \begin{tabular}{|l|} 
Captación \\
Real y su \\
$\%$ con respecto \\
a la meta \\
\end{tabular} & $\begin{array}{l}\text { Industrias } \\
\text { que } \\
\text { compraron }\end{array}$ & $\begin{array}{l}\text { Volumen } \\
\text { adquirido } \\
\text { Por cada } \\
\text { Industria }\end{array}$ & $\begin{array}{l}\text { Estado en el } \\
\text { que se } \\
\text { adquirió el } \\
\text { maíz }\end{array}$ \\
\hline $\begin{array}{l}\text { Primavera } \\
\text { Verano } \\
1997-97\end{array}$ & 703626 & $\begin{array}{l}\quad \text { Diferencia } \\
\text { Precio interno y } \\
\text { precio indiferencia } \\
-\quad \text { Bono de } \\
\text { Calidad } 25 \$ / \text { tn } \\
-\quad \text { prima } 73.24 \\
\$ / \text { tn }\end{array}$ & $\begin{array}{l}374419 \\
-53 \% \\
\end{array}$ & $\begin{array}{l}\text { Maseca } \\
\text { Minsa } \\
\text { Agroinsa }\end{array}$ & $\begin{array}{r}239629 \\
131046 \\
3744 \\
\end{array}$ & $\begin{array}{l}\text { Jalisco } \\
\text { México } \\
\text { Chiapas } \\
\text { Nayarit } \\
\end{array}$ \\
\hline $\begin{array}{l}\text { Otoño } \\
\text { Invierno } \\
1997-98\end{array}$ & 959488 & 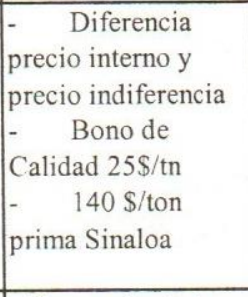 & $\begin{array}{l}885723 \\
-92 \% \\
\end{array}$ & $\begin{array}{l}\text { Maseca } \\
\text { Minsa } \\
\text { Agroinsa } \\
\end{array}$ & $\begin{array}{r}637720 \\
230288 \\
17744 \\
\end{array}$ & $\begin{array}{l}\text { Sinaloa } \\
-82 \% \\
\text { Tamps } \\
\\
-18 \% \\
\end{array}$ \\
\hline $\begin{array}{l}\text { Excedente } \\
\text { De comercializa } \\
\text { ción } \\
1997-98\end{array}$ & s.d. & $\begin{array}{l}\text { - Costo subastado } \\
\text { por industria arriba } \\
\text { del precio interno }\end{array}$ & \begin{tabular}{|l}
-276.5 miles \\
1 ra subasta \\
-213.4 miles \\
2da subasta
\end{tabular} & Sin dato & 489900 & $\begin{array}{l}\text { Sinaloa } \\
100 \% \\
\end{array}$ \\
\hline $\begin{array}{l}\text { Cierre de } \\
\text { presupuesto } \\
1998\end{array}$ & 1663114 & & 1750070 & $\begin{array}{l}\text { Maseca } \\
\text { Minsa } \\
\text { Agroinsa } \\
\text { Sin dato } \\
\end{array}$ & $\begin{array}{l}877348 \\
361334 \\
21458 \\
489900\end{array}$ & \begin{tabular}{|l} 
Sinaloa \\
$69.7 \%$ \\
Tamps \\
$9 \%$ \\
Jalisco \\
$9 \%$ \\
otros $12 \%$ \\
\end{tabular} \\
\hline
\end{tabular}

Fuente: Aserca 1999. "ASERCA 1998 principales resultados", en Claridades agropecuarias Octubre 1999. Un horizonte acerca del mercado agropecuario. México

(Maseca). La operación de los tres programas de apoyo se resume en el siguiente cuadro:

A esta situación no se ha llegado con actos conspiradores (las convocatorias y la información de Aserca han sido abiertas), sino como parte de las decisiones de política agrícola que empezaron con las compras de Conasupo en la década de los noventa, que alentaron un patrón de cultivos en Sinaloa y que luego fue fortalecido y defendido por una sociedad de productores que cuenta con un importante capital social.

El presupuesto que empleó Aserca para captar el volumen de Sinaloa, especificado en el cuadro 9, ascendió a 471.434 millones de pesos, que constituyeron el 61 por ciento del presupuesto nacional empleado por el organismo descentralizado.

Datos de los informes del gobierno de Sinaloa revelan que a partir de 1998 se generó un continuo apoyo de Aserca con este estado, cuyo causal no puede distinguirse con toda precisión: ¿es una política federal? ¿Es resultado de las presiones que realiza una sociedad organizada como la sinaloense? ¿Resolver la comercialización de maíz de Sinaloa es sólo una política inmediatista y pragmática, que aparece cada año, pero que al mantenerse crea una política estratégica no prevista? 


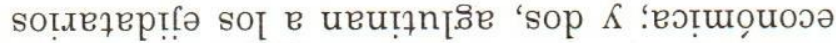

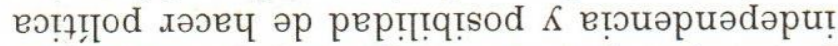

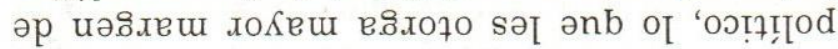

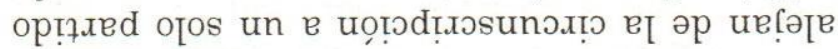

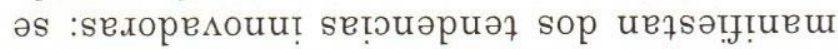

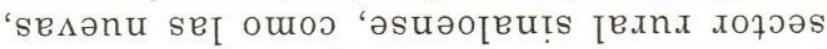

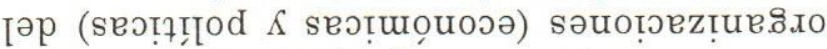
sefəț sei ołuez әnb xeqou әэеч opueno (666I) xе[़ฺ.̊̊

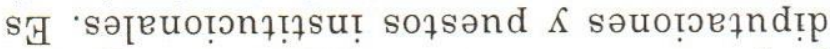

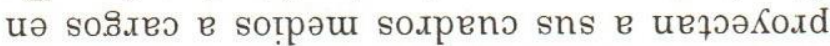

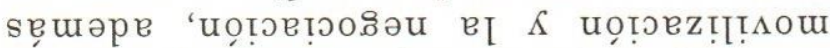

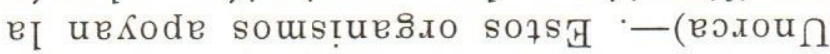
-оиеग[V) seuouọnt seuisədur

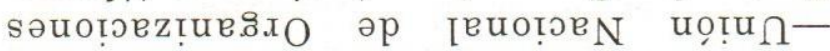

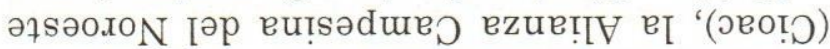

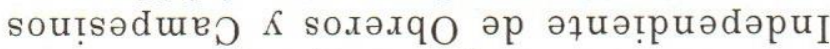

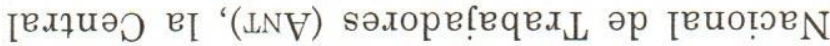

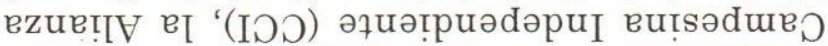

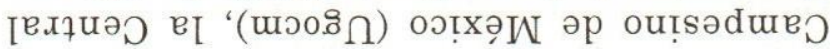

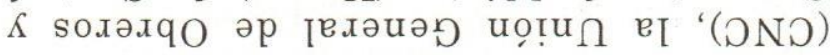

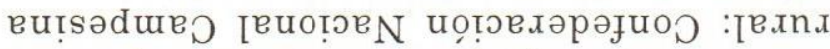

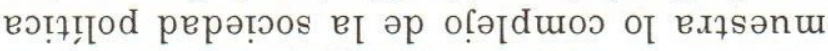

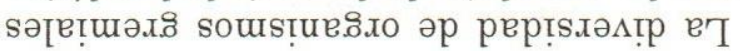

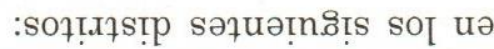

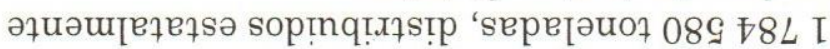

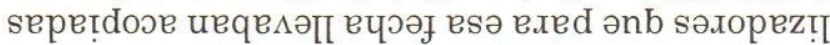

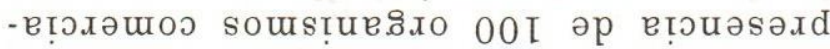

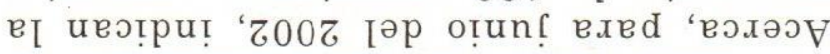

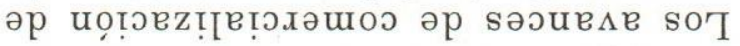

-o7sindnsəxd

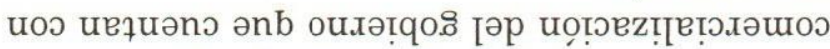

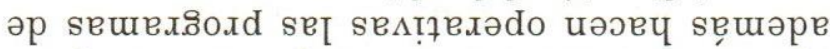

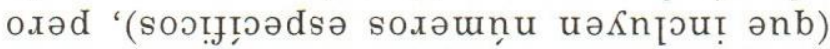

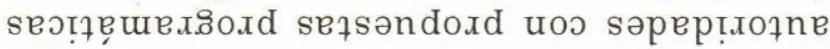

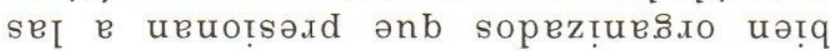

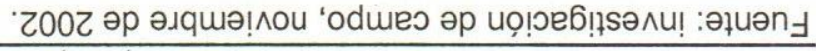

\begin{tabular}{|c|c|c|}
\hline $08 S^{\prime} \nabla 8 L^{\prime} L$ & opels $\exists$ & $00 \mathrm{~L}$ \\
\hline$\angle L O^{\prime} L E$ & znגo eך & \\
\hline$\angle 19^{\prime} 66 L$ & uẹวe!!nว & $0 \varepsilon$ \\
\hline 6ヤレ‘8ヤ & l!บગnumeng & $\angle L$ \\
\hline 9ヤレ゙ヤヤレ & ә^еsen & 12 \\
\hline 乙દ6‘દ8દ & s!บวow & $\nabla Z$ \\
\hline sepe|əuol & & sə|uәбе әр \\
\hline ope!dose uәun|о $\wedge$ & 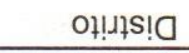 & oגəunn \\
\hline
\end{tabular}

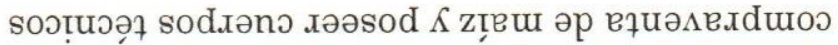

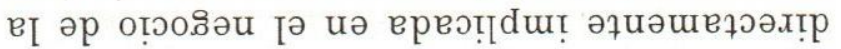

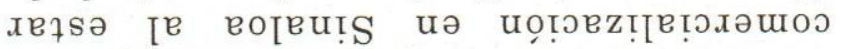

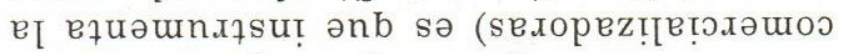

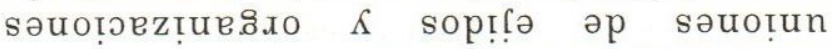
se ( әр ошол) ousțues.

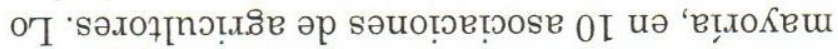

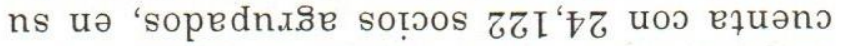

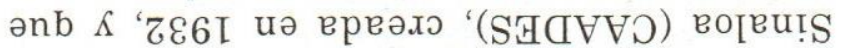
әр оредs द्र

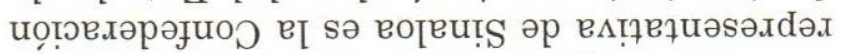

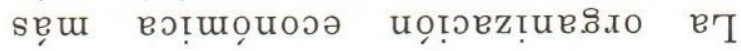

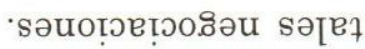

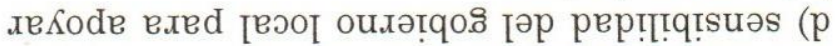

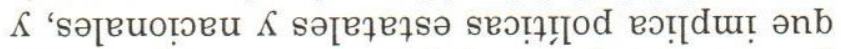

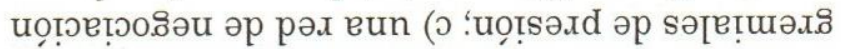

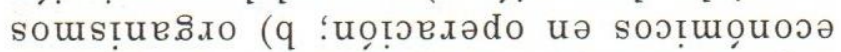

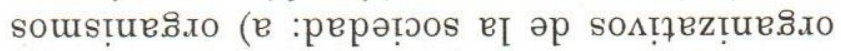

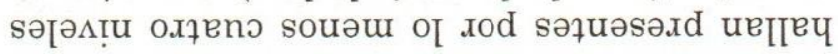

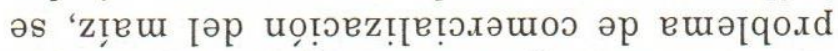

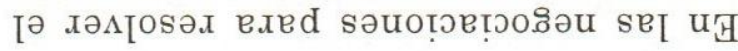

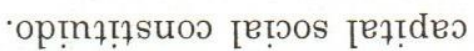

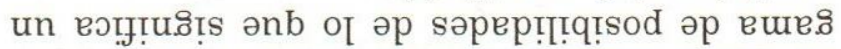

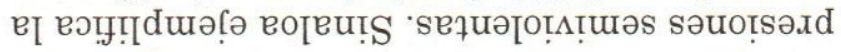

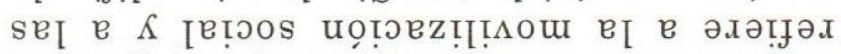

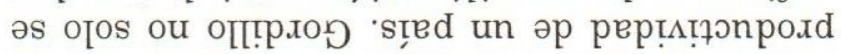

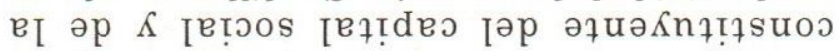

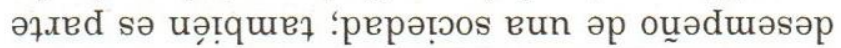

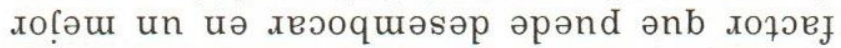

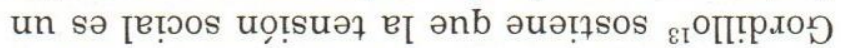

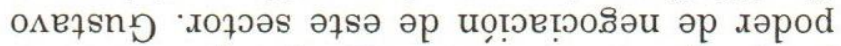

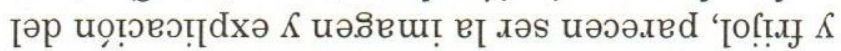

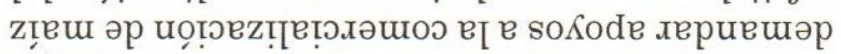

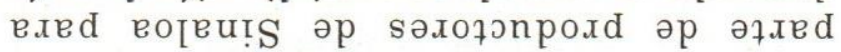

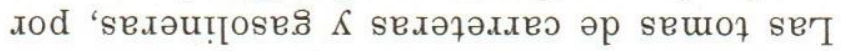

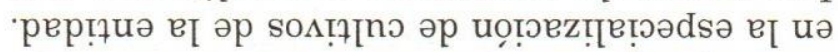

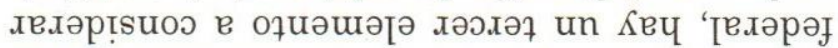

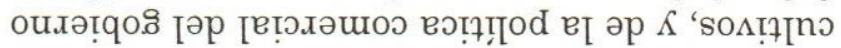

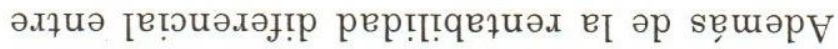

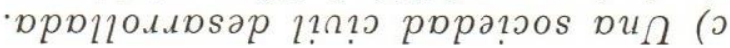

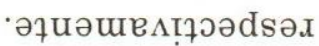

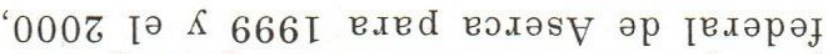

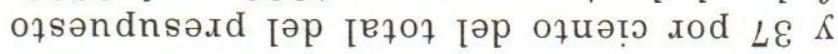

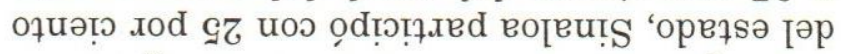

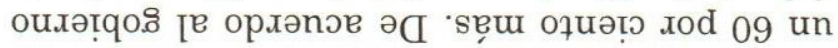

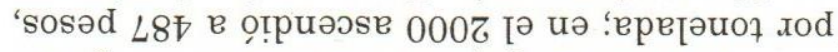

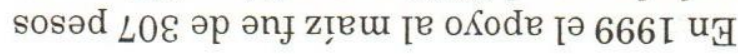

uọ!səud әp sodnı6 so| $\alpha$ po|pu! 
con los pequeños propietarios, lo que genera un nuevo actor que se define en torno a su quehacer y no a su adscripción a un tipo de tenencia de la tierra.

En Sinaloa la política económica, o economía política, se analiza, discute y negocia de forma escalonada y sistemáticamente. Las propuestas de los organismos comercializadores son llevadas al Comité de comercialización, convocado por el gobierno del Estado. Además, hay las reuniones con los diputados y senadores que salieron de Sinaloa y apoyan al sector. De esta forma se crea una serie de vasos comunicantes que vinculan los niveles de campo con las cámaras locales y con la legislación nacional, así como con organismos que toman las decisiones de presupuesto para apoyo a la comercialización. Aunado a esto, están los lazos entre políticos, las camarillas (política no formal) que posibilitan el acceso a información vital y, con ello, mayor posibilidad de negociación. Estas redes constituyen parte del capital social que posee Sinaloa y que en otros estados no tienen o sólo de forma fragmentada.

El inicio de la cosecha del maíz o frijol, como el inicio del período de pesca, son dos momentos importantes para el ambiente político de la entidad, ya que crea tensiones y apuros en los directivos de las instituciones sectoriales (Pesca, Sagarpa, Aserca), incluso el temor a ser tomadas sus instalaciones (con todo y funcionarios). La resolución de estos dos puntos de conflicto da señales a la sociedad de que "todo marcha bien". De modo que el manejo apropiado de estos movimientos puede generar un capital político para los gobernantes o soluciones que los lleven a perder credibilidad.

En este entorno, las iniciativas del Gobierno del Estado para darles cuerpo a los comités de comercialización y foros de discusión, así como el seguimiento que se da a estos aspectos en los informes de gobierno, muestran una clase política sensible y en posibilidades de colaborar a la resolución de estos problemas.
El contraste en cada uno de los niveles organizativos de la sociedad sinaloense, por ejemplo, con Jalisco, que tradicionalmente es el mayor productor de maíz, muestra la gran diferencia en capital social, y los resultados que de ello se derivan, en las negociaciones y en el posicionamiento comercial en México entre uno y otro estado.

\section{Conclusión:}

\section{nuevos arreglos institucionales}

Puede concluirse que la especialización de cultivos en Sinaloa, que tiende a impulsar granos como el maíz, frijol y sorgo, y a incrementar la competitividad internacional del jitomate, que con ello ha desplazado a cultivos como cártamo, soja, arroz y trigo, se deben a factores de mercado, al apoyo de la política estatal, así como a la presión y movilización de los productores hacia ciertos cultivos y, sobre todo, hacia la obtención de ciertos apoyos gubernamentales. La especialización productiva de Sinaloa se aparta de la disyuntiva: cultivos de importación versus cultivos de mercado interno, aunque ese proceso muestra la presencia de políticas de estado y presiones de actores que acentúan la diferenciación social intra e interregional, en la medida en que los subsidios muestran una selectiva direccionalidad regional.

\section{Notas}

1 Óscar Aguilar Soto. "Diecisiete años de producción maicera en Sinaloa, 1980-1997", Ciencia y Universidad, núm. 12 (3ra época), Instituto de Investigaciones Económicas y Sociales de la Universidad Autónoma de Sinaloa, junio 1999, Sinaloa, México, p. 109.

2 Sagarpa, Delegación Sinaloa, publicado en el Anexo estadistico, del Tercer Informe de Gobierno, C. Juan S. Millán, 2001, p. 120.

3 En este caso utilizamos un dato puntual, el del año agrícola de 1998, por lo que la importancia que se señala es relativa, ya que un año previo o uno después, la producción pasó al primer lugar o bajó, a lo más, al tercero. Esta situación pasa en los demás cultivos, por ejemplo, el frijol de Sinaloa al siguiente año dejó muy atrás la producción de Zacatecas y ocupó el primer lugar nacional en este producto. 
4 Los promedios trianuales permiten aminorar al máximo la expresión de un mal año agrícola en las comparaciones tendenciales que se realizan. Por ejemplo, si 1984 fue un mal año para la soja, ya que no se contó con agua disponible para su riego, tomar este dato y compararlo con 1998, haría ver que se parte de una muy baja producción de soja a inicios de los ochenta; si por el contrario utilizamos los datos contiguos a 1984 , que son 1983 y 1985 , y sacamos el promedio, la soja saldrá en su importancia histórica de inicios de los ochenta.

5 El análisis se realiza con ocho cultivos principales, del estudio que realizó Óscar Aguilar de Soto (1999), en "Los empresarios agrícolas en la producción de maíz de Sinaloa", Ciencia y Universidad, núm. 13/14 (3era época), IIES, Universidad Autónoma de Sinaloa, mayoagosto, septiembre-diciembre, p.159.

6 En 2000 la superficie cosechada total de riego fue de 712 mil hectáreas, lo que indica que esos cultivos hoy representarían 81 por ciento de esta superficie.

7 Juan de Dios Trujillo Félix. "Comportamiento de la agricultura de Sinaloa e innovación técnica”, en Ciencia y Universidad, núm. 9 (tercera época), febrero de 1997, Instituto de Investigaciones de Estudios Sociales, Universidad Autónoma de Sinaloa, p. 127.

8 Aguilar 1997 "Diecisiete años de...", op. cit. pp. 89-110.

9 Anuario estadístico del Informe de Gobierno de Sinaloa 2000. El dato es del ciclo otoño-invierno, 2000, p. 122.

10 Dato del año agrícola 1998; fuente: INEGI 2000. El sector alimentario en México.

11 En sentido estricto no se trata de nuevas reglas, sino de una nueva matriz institucional (llamada "de libre mercado") en la que se reordenan viejos arreglos, se refuncionalizan acuerdos, se inician nuevos arreglos, ya sea de tipo formal o informal.

12 Gonzalo Rodríguez G. "Tendencias de la producción agropecuaria en las dos últimas décadas", Revista Economía Mexicana, núm. 2, Centro de Investigaciones y Docencia Económica, México, 1983.

13 Gustavo Gordillo. "La ansiedad por concluir (la debilidad de las reformas estructurales en América Latina)", en Revista el mercado de valores, octubre de 1999, Nacional Financiera México. 1iv 